\section{Teaching children with Down's syndrome to read}

\section{Sue Buckley and Gillian Bird}

\author{
The Sarah Duffen Centre \\ Department of Psychology \\ University of Portsmouth
}

\section{Background}

We began investigating the reading skills of children with Down's syndrome in Portsmouth in 1980 after receiving a letter from a father, Leslie Duffen, describing how he had discovered that his daughter Sarah could begin to learn to read at the age of three years. Sarah was born with Down's syndrome. At three, she was just beginning to imitate and to use single words in her speech. Leslie taught Sarah to read on flashcards the words that he wanted her to be able to use in her speech and he observed that she began to use the words she had learned from the printed form at a faster rate than those she only experienced in the spoken form.

When Leslie wrote to us in 1979, Sarah was twelve years old and being educated in a local comprehensive school. She had received all but one year of her education in mainstream schools and was considered to be exceptionally able for a child with Down's syndrome. Leslie felt sure that her exceptional progress had been the result of teaching her to read early and that other children might be helped in the same way.

We found Leslie's letter surprising and intriguing. His experience with Sarah suggested that pre-school children with Down's syndrome could learn to read and that reading might be a "way-in" to language for these children. In 1979 children with Down's syndrome were not thought capable of learning to read at all by most professionals and there was very little research into the reasons for their spoken language difficulties. We certainly thought that Leslie's observations warranted further investigation.

With a grant from the Down's Syndrome Association we were able to appoint a teacher (Liz Wood) and set up a research study to begin to investigate these hypotheses. We followed the progress of fifteen pre-school children for three years while they received a regular home-teaching programme from us based on Portage.

Joanna, the first child that we tried teaching to read in 1980 , learned thirty words in a month at two years and six months of age. It was immediately clear that Leslie's observations with Sarah might well apply to other children with Down's syndrome and the Joseph Rowntree Foundation agreed to fund our work for a further year. The results of that first project have been published in full elsewhere (Buckley,1985a) as has an evaluation of the "parents as teachers" aspect (Buckley,1985b). We also published a video-tape illustrating this work in 1983, which is still available from us at The Sarah Duffen Centre.

\section{Early reading progress}

We now know that many children with Down's syndrome show the same ability as Sarah to begin to learn to read at an unusually early age. Our own early findings have been confirmed in published studies by Greene (1987) in Ireland and by Norris (1989) in Kent. We also receive many letters and reports from parents and practitioners who have successfully taught pre-school children to read by following our advice.

Our experience suggests that the majority of our children can learn to read single words by three to four years of age, some even earlier. The youngest child that we have actually taught ourselves, Joanna, learned her first words with great ease at two years and six months of age. Joanna found the task 
fun and would learn new words as fast as we produced them and with very little practice (we have this recorded on videotape in case any one is sceptical!).

Other children whose early progress we have recorded read their first words at the following ages:- Digby at two years one month, Emma and Daniel at two years four months, Zoe at three years five months and Jamie at three years six months. These children were all at the single word stage of speech, beginning to use a small number of single words appropriately, except for Digby. Digby began to learn to read before he could produce any spoken words. He demonstrated his comprehension by reading the flashcard and pointing to the correct object or picture.

All the children named above have continued to make steady progress with both reading and spoken language skills. They all have greater skills in these areas than is usually expected for children with Down's syndrome and all started school at five years of age in ordinary primary schools.

\section{Insights gained from our observations}

\section{Reading errors}

In the 1980 research project, we recorded the childrens' progress with their reading and while initially we were most surprised by the speed and accuracy of their performance (as clearly illustrated on the video record of Joanna mentioned above), we were even more surprised by some of the errors we began to see.

We expected the children to make visual errors i.e. to confuse words whichlooksimilar such ashair andrain orthis and shoe. These are the sorts of errors seen in the early performance of all beginning readers taught in this "look and say" way (Seymour \& Elder 1986) and we found them in our children's performance.

We did not anticipate the other consistent type of error that we observed when the children were reading single words, the semantic error. Here the word the child says has the same meaning as the one they are looking at but has no visual similarity. For example, the child looks at the printed word shut and says closed or looks at sleep and says go to bed. These semantic errors excited us at the time for two reasons.

Firstly, they suggested that the children were decoding the print for meaning and not just "barking at print" in a meaningless way as some critics were suggesting. They were reading single words on flashcards so had no available clues to meaning such as might be provided by pictures or the rest of a sentence. They must have decoded the printed word for meaning and then thought of a word which was linked by meaning to the target word on the card.

Secondly, the errors demonstrated that the brain could go straight from print to meaning, without changing the visual image of the word to its spoken form first and then accessing the meaning. In 1982, reading theorists were still arguing about whether the brain could actually do this. Our children were demonstrating that it could.

\section{Signing}

In 1982, signing was just beginning to be introduced to the the children we were working with learned sign at school, after we had taught them to read. We noticed two interesting effects of learning sign.

Firstly, that some of our children were able to sign the correct responses to flashcards without any extra teaching. We felt this was another clear illustration that they were not simply "barking at print" but were reading the print for meaning and able to replace the spoken response we had taught them with a sign entirely on their own initiative.

Secondly, that for some of the children signs were an easier and faster response mode than speech. They would look at a flashcard and appear to be concentrating on producing the correct spoken response, meanwhile their hands were already making a correct sign. This additional time needed to produce speech suggested to us that the children might have some sort of specific production difficulty with speech. Even when they knew what they wanted to say, they had difficulty in saying it.

This was one of the first clues we had to indicate that not all the language delay typical of children with Down's syndrome could be blamed on general cognitive delay. In fact the way in which the children substituted similar meaning words and signed when reading encouraged us to feel that they were more intelligent and had more understanding of language than they were being given credit for. What was beginning to emerge was the possibility that the children's language development was being delayed by a series of specific language learning difficulties in addition to the effects of any general cognitive delay.

\section{Pantomime}

When we watched the video-tapes on which we recorded the children's reading progress, we noticed that we had captured a number of sequences in which a child was trying to describe an experience or explain something to his mother for which his spoken language skills were inadequate. The child would resort to the combined use of single keywords and mime to try to convey his message. We were convinced again that the children knew what they wanted to say but could not express themselves in speech.

There are a number of possible hypotheses which could be generated to explain these observations. For example, the child may not have mastered enough grammar to be able to construct the sentences that were being implied by the combination of words and gesture. Alternatively, we could postulate that the child was thinking in sentences but could not execute them in speech.

Either way, we were fairly confident that the childrens' cognitive development was more advanced than their expressive language development from watching these sequences. This has since been confirmed by several studies For example, Cunningham and his colleagues demonstrated a lag between the childrens' mental ages and their language ages with expressive language falling even further behind than receptive language as the children got older (Cunningham et al.1985). Other studies have confirmed these findings and are discussed in the first article in this journal.

\section{Reading enhances speech}

Our own observations and those of many other parents and 
teachers (e.g. Carter, 1985 \& Norris, 1989) suggest that Leslie Duffen's original hypothesis was right and that reading is a "way-in" to their first language for these reading children.

Daniel's progress recorded by his home-teacher illustrates the effect of the early reading on his speech development.

Daniel's first spoken words were Daddy, teddy at 14 months and he was using some 50 single words at 2 years 3 months:

Daniel was introduced to flashcards by his home-teacher at 2 years 4 months and reading 10 flashcards at 2 years 6 months. He was reading two-word phrases at 2 years 8 months and these rapidly transferred to his speech.

At 2 years 10 months Daniel was reading 22 words and a month later he was reading six 3 word phrases which rapidly transferred to his speech. At 3 years 4 months he was reading 66 words and many 2 and 3 word combinations of these.

At 3 years 5 months he was reading simple books and the wordsand anda appeared in his speech. At 3 years 6 months Daniel was reading 4 word sentences and at 3 years 8 months he had a sight vocabulary of 116 words and was speaking in 6 word sentences. (Data taken from the records of Daniel's home teacher (Norris 1989)).

\section{The main benefits reported for speech}

New words learned on flashcards soon begin to emerge in the child's speech and may do so more quickly than words the child is only hearing.

Practising two-word and three-word utterances in reading accelerates their emergence in the childs speech.

Practising proper sentences in reading leads to the use of function words and increasingly correct grammar and syntax in speech. Mastering the rules of grammar and syntax is difficult for youngsters with Down's syndrome and many authors have drawn attention to this (see Fowler,A.1990 for a review).

The children who read early in this way achieve higher levels of literacy and linguistic competence than has hitherto been expected in children with Down's syndrome. Their "reading ages" are frequently close to their chronological ages up to eight or nine years of age.

Reading practice improves phonology and articulation.

\section{Why reading may help speaking}

Research has moved on since our original study and it is now possible to begin to build up a picture of some of the specific learning difficulties which delay the language development of children with Down's syndrome. As you read the list, I think you will begin to see why learning to read may help the children overcome some of their difficulties.

\section{Hearing loss}

In the last ten years, a number of studies report a high incidence of significant hearing loss in young children with Down's syndrome which may be affecting the language development of as many as $80 \%$ of infants and toddlers (Cunningham \& McArthur 1981). Such losses, even if transitory due to otitis media, will obviously make learning language from listening difficult for the child.

\section{Specific modality effect}

A number of studies have demonstrated that the children perform better when tasks are presented visually rather than auditorily and when the response can be made manually by pointing or selecting rather than orally (see Pueschel et al 1988 for a review). This general finding indicates that the impairments in auditory processing due to hearing loss, poor auditory discrimination and limited auditory memory and the impairments in the complex mechanisms of speech production are limiting the children's performance.

\section{Auditory short term memory}

Recent studies have demonstrated poor development of auditory short-term memory span relative to cognitive development throughout childhood (Mackenzie \& Hulme $1987,1992)$ This will make sentence processing and hence the learning of grammar and syntax from listening particularly difficult for the child and may explain why most children with Down's syndrome are still speaking in immature keyword utterances even in their teens.

\section{Visual memory}

In children with Down's syndrome visual memory may be more effective than their auditory memory for short sequences of information. This is the reverse of the development seen in ordinary children where auditory memory is better than visual memory. (Marcell \& Armstrong 1982, Marcell \& Weeks 1988). Better visual memory may be one reason why children with Down's syndrome enjoy learning with a computer, which presents information visually.

We think that other reasons for the benefits of computeraided learning are that it is under the child's control so gives them as much time as they need to think and organise their responses, before assuming failure or asking another question in the way an adult might. The computer also always rewards success and never gets irritated! Computer programmes designed to teach speech have received a lot of attention in the U.S.A. (see Meyers 1988,1990). There are also many useful programmes to teach reading and writing skills. (See some suggestions on page 40).

\section{Speech production}

Various authors are drawing attention to speech-motor delay and difficulty affecting the children's ability to speak clearly. The progress of early signers, who often sign extensively for some months before they begin to speak, suggests a specific word production problem (LePrevost 1986). The growing gap between the level of language comprehension and their expressive ability in most children with Down's syndrome has also been reported by Miller (1988) and by Christine Jenkins in this issue suggesting continuing production difficulties as they get older.

It is likely that research to date has only just begun to identify the range of specific learning difficulties associated with Down's syndrome as they affect language learning. However the reader will see that the child with Down's syndrome may have great difficulty in learning language in the usual way i.e. from listening to adult speech. He or she is also going to experience difficulty in communicating orally. Teaching strategies will need try to overcome specific difficulties and to build on the child's strengths. Signing and reading approaches clearly do this and lead to success. 


\section{Beginning later}

Not all children with Down's syndrome are going to be able to make an early start with reading. Many ordinary children are not able to begin to learn to read in their pre-school years, the range in normal reading development is wide with some children starting in their pre-school years and others not until they are eight or nine. We would expect the same range in children with Down's syndrome. Children who start later may make rapid progress and become good readers. We know teenagers who are now reading for pleasure but did not show any interest in reading until they were eight or nine years old.

Symbol systems such as Rebus or Makaton symbols can be used for the children who are not able to master print and should bring the same benefits for speech development. However we would always try print with a child first and only use symbols if he or she cannot master print. Symbols are not a stepping stone to print, they are an alternative and different system and most children do not need to learn them.

The earlier the child can make a start with reading, the greater the benefit for their speech and language skills, but there will be language benefits whenever they start.

\section{Teenagers}

The advantage of reading for language learning has been demonstrated in our own work with older children. In a study designed to investigate the possibility of improving the spoken language skills of a group of teenagers, two teaching methods were compared. The methods and materials used were identical except for the addition of printed sentences on the picture cards used in the "reading" condition.

The teenagers learned faster and more accurately in the "reading" condition for every structure taught. Contrary to our expectations, the advantageous effect of the "reading" condition was most dramatic for some of the least able teenagers. They learned twice as fast in this condition even though non-readers at the outset of the study!

There seem to be two reasons for this. These teenagers had very poor short-term auditory memories and some were therefore simply not able to remember and repeat the sentences they were learning if they only heard them. A further experiment indicated that the effect of the print was due to storing the visual image of the word, not just to the enhanced practice possible in the visual condition. (This research will be reported in full in the next issue of the Journal).

\section{Teaching reading to teach language}

While the idea of teaching reading to teach spoken language still meets with resistance from some teachers, it has been used successfully for more than twenty-five years in some areas of special education in the UK and I would urge all teachers to read Ella Hutt's detailed and insightful account of this approach (Hutt 1986). We have made extensive use of her methods and "Language through Reading" materials since visiting her in 1982.

\section{Teaching principles}

We use exactly the same principles to develop teaching programmes whatever the age of the child, teenager or young adult. The methods are based on experience and on the findings of research into the development of reading skills in ordinary children and adults.

\section{Reading readiness}

We have found no way of predicting a child'spotential for reading or readiness to read. In our view both concepts are meaningless. Many of the children we know who have made great progress with reading would have failed all the usual readiness tests at the outset. The only way we know of determining whether a child with a learning disability is able to learn to read is to try teaching them in the ways we suggest. The only way to find out how far they may progress is to continue to teach them.

If you use the errorless learning approach that we advocate below and make the tasks fun you can do no harm by trying some reading activities with any child. If they make no progress after a few games, leave it and try again in a month or two. Meanwhile keep reading interesting stories to the child and keep labels on everyday items and names on hooks etc. so that print is a natural part of their world.

\section{Establish a sight vocabulary}

The first words chosen for flash cards are usually family names and then words that we know the child comprehends and uses. The words are printed neatly on flashcards by hand in lower case and without any pictures. Our own experience and that of researchers working with ordinary children shows that the children learn to read words faster without pictures to distract them (e.g. Samuels 1967). They are all taught to read their first words by a carefully structured behavioural approach which emphasises the importance of task analysis, teaching in small steps, using an errorless learning method and social reinforcement.

\section{Matching, selecting and naming}

The children learn first to match the words by playing matching games with the flashcards, then to select them when asked for them by spoken name and finally to "name" or read them. As the children's sight vocabularies grow so does their understanding of the complete task and they become increasingly able to learn to read new words without the need to break the task into the three steps. We break the early reading task into its component parts deliberately, in order to help the child understand each step in the task. In so doing, we will be able to see the reason for the child's failure from the step in the task that he or she cannot master.

\section{Errorless learning}

We also advocate errorless learning as the best way of building success and self-confidence at the task for the child. Errorless learning simply means teaching the child to complete the new task by guiding them through each step correctly with prompts and not allowing them to fail. As the child becomes more confident the teacher fades the prompts until the child can do the whole task without help. In our early work, we found that it seemed to be difficult for the children to correct wrong responses, more difficult than for ordinary children, so it was important to prevent wrong guesses in the initial stages of learning. Jennifer Wishart's research on aspects of early cognitive development in children with Down's syndrome has drawn attention to the children's sensitivity to failure and lack of consolidation strategies when learning. She also advocates errorless learning as the preferred teaching method for our children (Wishart 1988). 


\section{New words for phrases and sentences}

Once we know that the child is able to establish a sight vocabulary in this way, we will introduce words into their flashcard vocabulary that they do not yet comprehend or use in their speech. For these words, games are played and activities devised to teach the children the meanings. These words are chosen to enable us to build phrases and sentences for the children to practise. The choice of phrases and sentences is determined by the child's level of spoken language use. In this way, we use the reading to enable the child to practise the words, phrases and sentences which he or she needs to develop their spontaneous speech skills and master the rules for grammar and syntax.

\section{The meanings of words}

The reading work is not going on in isolation from a whole range of other games and activities designed to help the child to learn the meanings of the words and how to use them in communicative interactions. For all children, an understanding of the meanings of words and the ways in which they are used grows slowly. At first, "cat" will be used as a label for the child's own cat. It will take time and experience of many different cats before the child realises it's a label for a class of objects. Indeed even as adults we will be adding to our knowledge of the cat family and thus extending the concept behind the label. Childrens' understanding of words grows with using them and then having their utterances expanded or corrected.

\section{Understanding sentences}

It is easy to teach a sight vocabulary so that the child can read a sentence aloud correctly but not comprehend it as the grammar and syntax are too advanced for them. Once the teacher is aware of the level of the child's language comprehension skills this does not happen as the reason for the child's comprehension difficulty is understood and stories can be chosen which use grammar and syntax that is within their current comprehension level. We encourage parents and teachers to make simple books based on the child's own experiences and to write sentences with the child's spoken language needs in mind so that they are reading words, phrases and sentences which will help them to talk more clearly.

\section{Phonics}

We encourage early success and confidence in this "look and say" whole word way and then move on to give the children a more sophisticated understanding of the reading process by pointing out the letter-sound correspondences in the words that they can already read correctly. Knowledge of letter sounds enables a child to work out an unfamiliar printed word by themselves. We draw their attention to the initial or onset sounds by finding two words in their sight vocabulary with the same initial or onset sounds. Recent work has suggested that children break the words into onset and rime such as str and ing forstring, str being the onset and ing the rime (Goswami \& Bryant 1990). In 1982 we observed that our early readers were breaking the words up in this way for themselves as their experience with reading words grew.

Research suggests that once a printed word is familiar, the brain recognises it as a whole word and goes straight from print to meaning (Ellis \& Young 1988). So a child can learn to read and read successfully without having any understanding of letter-sound correspondences at all, providing someone is on hand to teach every new word. There is no limit to the size of the vocabulary that can be established in this "look and say" way.

However most children with Down's syndrome are able to learn some letter-sound rules and therefore help themselves to tackle new words in their reading and also to spell when writing. Some researchers believe that phonic knowledge is more important for spelling than reading (Frith 1980). Uta Frith suggests that most children learn to understand and use phonics from their own experience as they progress with their reading and writing. Teaching letter-sounds as an activity isolated from the reading task is less likely to help the child realise the relevance of the knowledge.

Any reader interested in recent research into reading and spelling development in children would find Margaret Snowling's book "Dyslexia" (Snowling 198) a readable introduction containing information relevant to teaching any child to read.

\section{Reading and talking}

Our young children with Down's syndrome are learning to read and to talk at the same time, the two skills interacting and informing each other, as indeed they do for all children. As Garton and Pratt point out in their important book, "Learning to be Literate", the development of written language skills influences spoken ability, as new language structures and functions are learned for writing which in turn are adopted for speaking (Garton \& Pratt,1989 p.2).

The difference for our children compared to ordinary children is that they are being exposed to reading at a much earlier stage in their language development. This means that they are more dependent on direct and accurate visual decoding skills and using the direct visual route to the meaning of the word than the ordinary five year old as they do not have enough knowledge of spoken language to guess an unfamiliar printed word from the context provided by a sentence or a picture. They may also not have enough knowledge of phonics to "sound out" words initially. The way in which any child tackles a new task will vary according to the knowledge and skills that they have available to them.

\section{Teaching in the UK}

In the UK, most children with Down's syndrome are still being educated in special schools for children with learning difficulty, though the situation is changing fast. In many areas the younger children are joining mainstream schools. The teaching of reading is not a priority in the early curriculum of most special schools though this situation is beginning to change.

The children in mainstream schools are more likely to be learning to read though the teachers may not have access to advice regarding the need to take account of the child's language comprehension level or the way in which reading can be used to improve speech.

At present parents are often the driving force and teach their child to read at home. All the children mentioned earlier in this article were taught by their parents, following our advice. The following extracts from a letter from a parent describes the benefits she observed for her daughter.

"I started to teach Emma to read after hearing you talk in Bristol 
seven years ago. She was then two years and four months of age. Emma is now nine years old and an able and avid reader. She attends our large local mainstream primary school and holds her own well in the second year junior class. She seems to develop in leaps and bounds. Being able to read has done so much for her.

"It helped her speech. For example when she began to read at age two, she spoke understandably but imperfectly as she left out the definite and indefinite articles, prepositions etc. The change came when she was able to sentence build in flashcards. Today her speech is mature and her teacher commented at the last parents evening that the extent of her vocabulary and her turn of phrase would leave many in the class standing.

"It helped in the way other children regarded Emma and not least her own self-esteem. They knew and she knew that in reading she was amongst the best in the class. This apparently less able child wasn't so less able after all!

"Emma is now an independent reader and books give her so much. She wakes early and reads for at least one hour every morning. She makes her own choice of book but everything she reads fulfils her - she chuckles when reading 'The Twits' and cries over 'Heidi'. These are her two favourite books at the moment and she reads them over and over again. Equally however she will read poems or her atlas, history book, nature book etc. from which she teaches herself. She loves her Bible. She is very proud when her five year old sister carries the newspaper to her and asks 'What time is .......... on the television?' . She is always able to tell her and I feel Sarah, who I feel senses rather than knows of Emma's differences , is thrilled with the sense of her big sister having the "big sister' image for once."

\section{References}

Buckley,S.J. (1985a) Attaining basic educational skills. Chapter in Lane,D.\&Stratford,B. (Eds) Current approaches to Down's syndrome. Holt Saunders.

Buckley,S.J. (1985b) Teaching parents to teach reading to teach language. In Wolfendale,S. \& Topping,K. Parental involvement in childrens reading. Croom Helm.

Carter, S. (1985) Darwins World of Books. The Exceptional Child.

Cunningham,C.C. Glenn,S.M. Wilkinson,P. \& Sloper,P. (1985) Mental ability, symbolic play and receptive expressive language of young children with Down's syndrome. Journal of Child Psychology and Psychiatry, 26 (2) 255-265. Cunningham,C. \& McArthur,K.(1981) Hearing loss and treatment in young Down's syndrome children, Child:H ealth, Care and Development, 7.357.

Ellis, A.E. \& Young,A.W. (1988)Human cognitive neuropsychology. Hove: Lawrence Erlbaum Associates.

Frith U (1980) Cognitive processes in spelling. Academic Press

Fowler,A. (1990) Language abilities in children with Down's syndrome: evidence for a syntactic delay. In Cicchetti,D. \& Beeghly,M. (Eds) Children with Down Syndrome. Cambridge: Cambridge University Press.
Garton,A. \& Pratt,C.(1989)Learning to be literate:the development of written and spoken language. Oxford:Blackwell. Green,K. (1987) Involving parents in teaching reading: a project with nine children with Down's syndrome. Mental Handicap, v.15,p.112-115.

Goswami,U \& Bryant,P. (1990) Phonological skills and Learning to read. Oxford: Blackwell

Goswami,U. (1992) Phonological factors in spelling development. Journal of Child Psychology and Psychiatry, 33.6. 967-976.

Hutt,E. (1986)Teaching Language-disordered children: a structured curriculum. London: Edward Arnold.

LePrevost,P. (1986) The use of signing to encourage first words. In Buckley,S., Emslie,M., Haslegrave,G. \& LePrevost,P. The development of language and reading skills in children with Down's syndrome. Portsmouth Polytechnic.

MacKenzie,S. \& Hulme,C. (1987) Memory span development in Down's syndrome, severely subnormal and normal subjects. Cognitive Neuropsychology ,v.4,p.303-319.

MacKenzie,S. \& Hulme,C. (1992) Working memory and severe learning difficulties. Hove:Lawrence Earlbaum Associates.

Marcell,M.M. \& Armstrong,V. (1982) Auditory and visual sequential memory of Down syndrome and non-retarded children. American Journal of Mental Deficiency, 87 (1).8695.

Marcell,M.M. \& Weeks,S.L.(1988) Short-term memory difficulties and Down's syndrome. Journal of Mental Deficiency Research, 32 153-162

Meyers,L. (1988) Using computers to teach children with Down's syndrome spoken and written language skills. In Nadel.L.(Ed): The psychobiology of Down's syndrome. New York: NDSS.

Meyers,L. (1990) Language development and intervention. In Van Dyke,D.C. et al. (Eds) Clinical Perspectives in the Management of Down's syndrome. New York: SpringerVerlag.

Miller.J. (1987) Language and communication characteristics of children with Down syndrome. In Pueschel,S.M. et al. (Eds) New Perspectives on Down Syndrome. Baltimore: Paul Brookes.

Miller.J. (1988) The developmental asynchrony of language development in children with Down syndrome in Nadel, L. ( Ed) The psychobiology of Downs syndrome, Bradford.

Norris,H. (1989) Teaching reading to help develop language in very young children with Down's syndrome. Paper presented at the National Portage Conference. Peterborough. (To be published in Conference Proceedings).

Pueschel,S. (1988) Visual and auditory processing in children with Down syndrome. In Nadel.L. (Ed) The Psychobiology of Down Syndrome. New York: NDSS.

Samuels,S.J.(1967) Attention process in reading: the effect of pictures on the aquisition of reading responses. Journal of Educational Psychology 58

Seymour,P.\& Elder,L (1986) Beginning reading without phonology. Cognitve Neuropsychology, v.3,p.1-36.

Wishart,J. (1988) Early learning in infants and young children with Down's syndrome. In Nadel.L. (Ed) The psychobiology of Down syndrome. New York: NDSS. 